Running head: VISUAL EXPLORATION OF SEMANTIC MARKERS OF FAITH

Visual Exploration of the Semantic Markers of Faith

Author Note

Denise A. D. Bedford, Goodyear Professor of Knowledge Management, Kent State University

Correspondence concerning this article should be addressed to Denise A. D. Bedford, Information Architecture and Knowledge Management, School of Library and Information Sciences, Kent State University, Kent Ohio 44242-0001. E-mail: dbedfor3@kent.edu 


\begin{abstract}
Faith is a term which defies precise definition, yet as a concept it has rich and deep semantic meaning. Faith is a universal spiritual concept associated with all of the World's religions. Through historical study, we can trace the history of faith within and across those religions. Is it possible to see faith from an information perspective or can faith be understood only as tacit knowledge and belief? The research question which this work addresses is: Is it possible to create a single visual representation of faith that is meaningful to and understandable by members of many religious faiths? This paper explores the representation of faith across religions through the visual presentation and mapping of semantic markers. Semantic markers are defined as meaningful concepts that trigger an association with a core idea. Semantic markers of faith are derived from sacred religious texts using natural language processing (part of speech tagging) and grammatical concept extraction. Sacred texts are identified for each religions including: Christianity, Islam, Buddhism, Hinduism, Jainism, and Taoism. The markers and their relationships are visually mapped based on the frequency of occurrence. Semantic markers are represented as word clouds. Word clouds are created for each religion individually, and as a single combined cloud for all religions. The individual word clouds illustrate the role of faith in the religion based on the richness or sparseness of the semantics. Through comparisons, the individual clouds also highlight variations in the role of faith across religions. The composite word clouds for all six religions illustrate the common elements of faith.
\end{abstract}




\section{VISUAL EXPLORATION OF SEMANTIC MARKERS OF FAITH}

\section{Research Goals}

Religious beliefs define what we believe in spiritually, how we understand we should behave, and what truths we accept. Different religions interpret belief in different ways. Faith is closely associated with religious beliefs. Faith is a universal spiritual concept that plays a role in all of the World's religions. History tells us, though, that there are different interpretations and characterizations of faith across religions. Faith may be a stronger concept in those religions which are belief-oriented. Members of belief-oriented religions accept and adhere to the beliefs that ground that religion. Other religions may have beliefs, but those beliefs are not a determining factor in membership.

All religions address some aspect of faith, though perhaps in different ways and to different degrees. Faith may be associated with belief in divinity(ies), with hope, explanation of mysteries or things not seen, acceptance, personal convictions, trust, moral behavior or doctrine, and responsibilities and obligations of members of the faith.

Table 1.

Common Definitions of Faith in Belief Systems

\begin{tabular}{|l|l|}
\hline \multicolumn{1}{|c|}{ Belief systems } & \multicolumn{1}{c|}{ Sacred texts } \\
\hline Baha'i & Bayan \\
\hline Buddhism & Four noble truths \\
\hline Christianity & Bible (Old and New Testament) \\
\hline Confucianism & The Five Classics, Four Books \\
\hline Hinduism & Vedas, Upanishads, Bhagavad-Gita \\
\hline Indigenous Indian religions & Recorded myths and legends \\
\hline Islam & Qur'an \\
\hline Jainism & Agamas Akaranga Sutra, Kalpa Sutra \\
\hline Judaism & Hebrew Bible/Old testament, Talmud \\
\hline Shintoism & Kohiki, Nihon-gi \\
\hline
\end{tabular}


VISUAL EXPLORATION OF SEMANTIC MARKERS OF FAITH

\begin{tabular}{|l|l|}
\hline Sikhism & Adi granth \\
\hline Taoism & Tao-Te Ching, Taoist Texts Parts 1,2 \\
\hline Zoroastrianism & Avasta \\
\hline
\end{tabular}

We can explore common elements and differences in Faith across religions through study of sacred texts, in dialog with religious leaders and by reading the scholarly literature. However, this approach requires intense intellectual engagement and is subject to individual interpretation. This research explores whether a semantically-based visual presentation of faith across religions is an effective way of understanding commonalities and differences.

This research is exploratory in nature. The research methodology should be regarded as preliminary and open to critical review. The intent of the research is not to define faith in a rigorous way but to consider a new way of exploring the concept. The expectation is that the research results will stimulate discussion about faith among members of different religions.

\section{Research Questions}

This research explores three questions, including:

- Question 1. Is it possible to create a visual representation of faith drawing upon the use of key semantic markers in the sacred texts of a religion?

- Question 2. Are commonalities and variations in the concept of faith visible in the visual representation?

- Question 3. Is the visual representation of faith meaningful to members and nonmembers of the religions that are represented?

\section{Research Methodology}

A five step methodology was adopted to explore the research questions. Each of the five steps is discussed in detail below. 


\section{VISUAL EXPLORATION OF SEMANTIC MARKERS OF FAITH}

- Step 1. Adopt a broad definition of faith in terms of its basic semantic markers.

- Step 2. Assemble a collection of sacred texts of the world's major religions and belief systems.

- Step 3. Create a set of semantic concepts that represent the concept of faith in a religion by identifying and extracting explicit references in sacred texts .

- Step 4. Generate a word cloud for each religion, based on the extracted markers;

- Step 5. Generate a composite word cloud for all religions, based on a combined list of semantic markers.

\section{Step 1. Adopt a Semantic Definition of Faith}

In order to undertake a semantic analysis of faith in sacred religious texts, we must begin with a semantic definition of faith. By a semantic definition we mean those concepts that define the essential aspects of faith. We identified five semantic concepts - faith, belief, trust, allegiance and assurance. The semantic profile of faith was constructed around the lexical variants of these five concepts. An automated categorization profile was constructed around the definition (Figure 1). The categorization profile was implemented using the SAS/Content Categorization Suite technology. 
Figure 1

SAS Categorization Profile for Faith

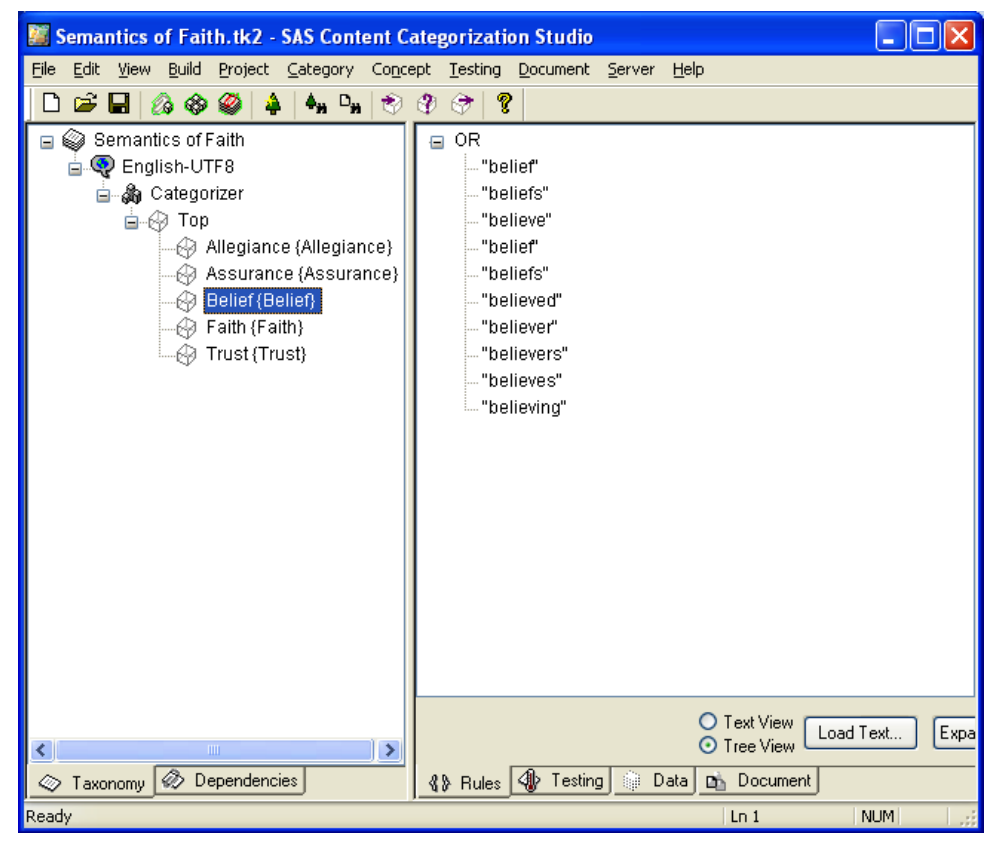

\section{Step 2. Assemble a Collection of Sacred Texts}

Uncovering the semantics of faith - in this research effort - means discovering the context in which faith is referenced. Primary sources provide the most important context for our analysis. At least one primary sacred text was identified for each of the religions (Table 1). Many of the sacred texts were available in digital form on the web. Others were available in print format. The latter were photocopied and optically scanned to create digitally readable copies. Copies were made to support semantic analysis.

\section{Step 3. Create Lists of Semantic Concepts for Each Religion}

Most word clouds are generated from single words. They leverage statistical clustering methods that begin with single concept extraction. For this research, the context was critical for understanding the meaning of faith. In order to preserve context, it was necessary to extract more than the simple occurrence of the words. It was necessary to extract the phrases or 
VISUAL EXPLORATION OF SEMANTIC MARKERS OF FAITH

sentences in which they occurred. The New Strong's Expanded Exhaustive Concordance of the Bible (Strong 2010) was used as a minimal threshold for phrase extraction.

Two methods were used to extract phrases and sentences. Where the text was available as a distinct digital object, the content was converted to plain text and processed against the automated categorization profile. Where the sacred text was available as a searchable resource on the web, the semantic concepts were individually searched. The phrase and sentence in which the concept appeared were manually copied to a list for each religion (Figure 1).

Figure 1.

Sample Extraction from Christian Concepts for Faith

ABOUT_HIM_EVERYONE_WHO_BELIEVES

ABRAHAM_BELIEVED_GOD

ABRAHAM_BELIEVED_LORD_

ABRAHAM_IN_HOPE_BELIEVED

ABRAHAM'S_FAITH_WAS_CREDITED

ACCEPT_HIM_WHOSE_FAITH_WEAK

ACCESS_BY_FAITH_INTO_HIS_GRACE

ACCOUNTING_TO_YOUR_FAITH_WILL_IT_BE_DONE

AL_THIS_TAKE_UP_SHIELD_OF_FAITH

ALL_NATIONS_MIGHT_BELIEVE

ALL_THAT_HEZEKIAH_HAD_SO_FAITHFULLY_DONE

ALL_BELIEVERS_WERE_ONE_IN_HEART

ALL_BELIEVERS_WERE_TOGETHER

ALONG_WITH_ABRAHAM_MAN_OF_FAITH 
VISUAL EXPLORATION OF SEMANTIC MARKERS OF FAITH

\section{ALONG_WITH_FAITH_LOVE_THAT_ARE_ ALONG_WITH_SOME_OTHER_BELIEVERS}

The phrases were pruned and formatted for visual clustering and presentation. Pruning included the deliberate removal of such common words as articles (i.e., the, an, a, that, there, this), and conjunctions (i.e., but, for, and, nor, or, yet, so, both, whether, just). Pronouns, adverbs, adjectives, nouns, and verbs were deliberately retained because they added meaning to the context. Redundancies or repetitions of phrases were not removed from the lists as they provide important indicators of frequency and weight All words were converted to uppercase to facilitate human reading.

\section{Step 4. Generate a word cloud for each religion, based on the extracted markers}

Individual lists were fed into Wordl (http://www.wordl.net) a publicly available word cloud engine. Parameters for visualizations were set to avoid removal of any additional common words. Layouts were chosen to facilitate human review and evaluation of all concepts. The word clouds display all of the concepts in the list. The size of each word is proportional to the frequency of its occurrence in the list. In this case, occurrence would be in any of the phrases extracted. Some word clouds are denser than others because the base concept lists are richer.

A word cloud was created for each religion. Three displays of each list were generated to provide multiple views and perspective for analysis. Individual word clouds are available in digital format upon request from the author.

\section{Step 5. Composite word cloud for all religions was created.}

The lists of concepts from all six religions were integrated into a single list. The composite list was used to generate a composite word cloud. 
VISUAL EXPLORATION OF SEMANTIC MARKERS OF FAITH

\section{Research Data}

Table 2.

Number of Semantic Markers Extracted from Sacred Texts

\begin{tabular}{|l|c|}
\hline \multicolumn{1}{|c|}{ Belief systems } & $\begin{array}{c}\text { Number of Semantic } \\
\text { Markers }\end{array}$ \\
\hline Taoism & 12 \\
\hline Hinduism & 145 \\
\hline Jainism & 38 \\
\hline Islam & 454 \\
\hline Christianity & 783 \\
\hline Buddhism & 92 \\
\hline
\end{tabular}

\section{Research Results for Individual Religions}

The research results take the form of seven word clouds, one cloud for each of the six individual religions and a composite cloud for cross-religion concepts. Each cloud is displayed and discussed individually.

\section{Word Cloud for Christianity}

The list of faith related concepts was richest for the Christian religion. All five aspects of faith were found in the sacred text. To the viewer, the density of the word cloud (Figure 2) suggests that faith is an important concept. Belief and faith are central concepts but there are many lesser supporting concepts surround them. Many of the secondary concepts appear to be lexical variants of the core factors. This suggests a deeper treatment of faith within the sacred texts. 
Figure 2.

Word Cloud for Faith in Christian Religion

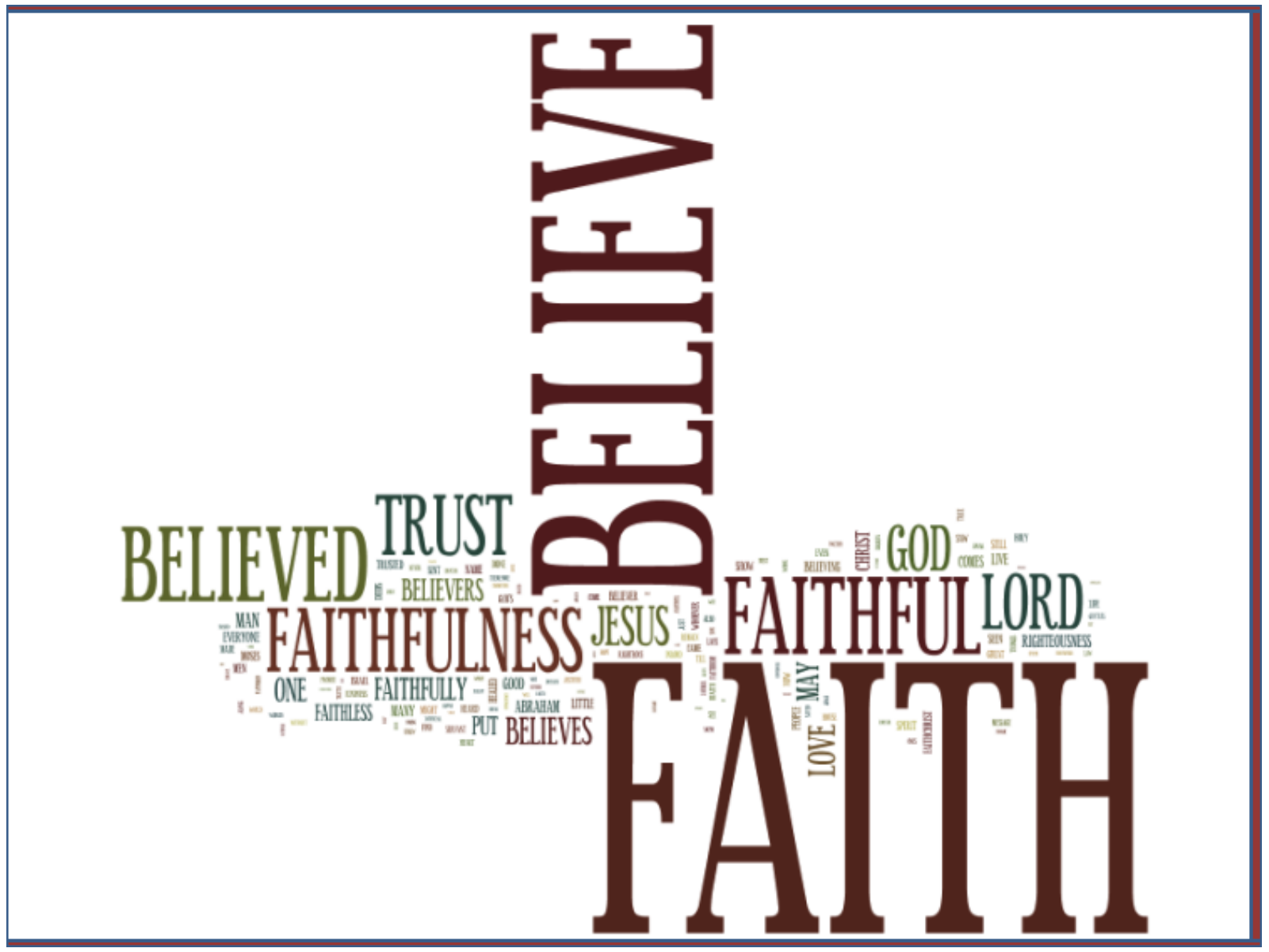

\section{Word Cloud for Buddhism}

The word cloud for faith in Buddhism is much less dense (Figure 3). There is a smaller set of concepts represented in the sacred texts. There are fewer variations on the basic concept of faith, and more references to the other concepts such as truth, trust and belief. The appearance of verbs and other references to actions are of interest in this word cloud. This suggests that in Buddhism faith may be related to behavior. 
Figure 3.

Word Cloud for Faith in Buddhism

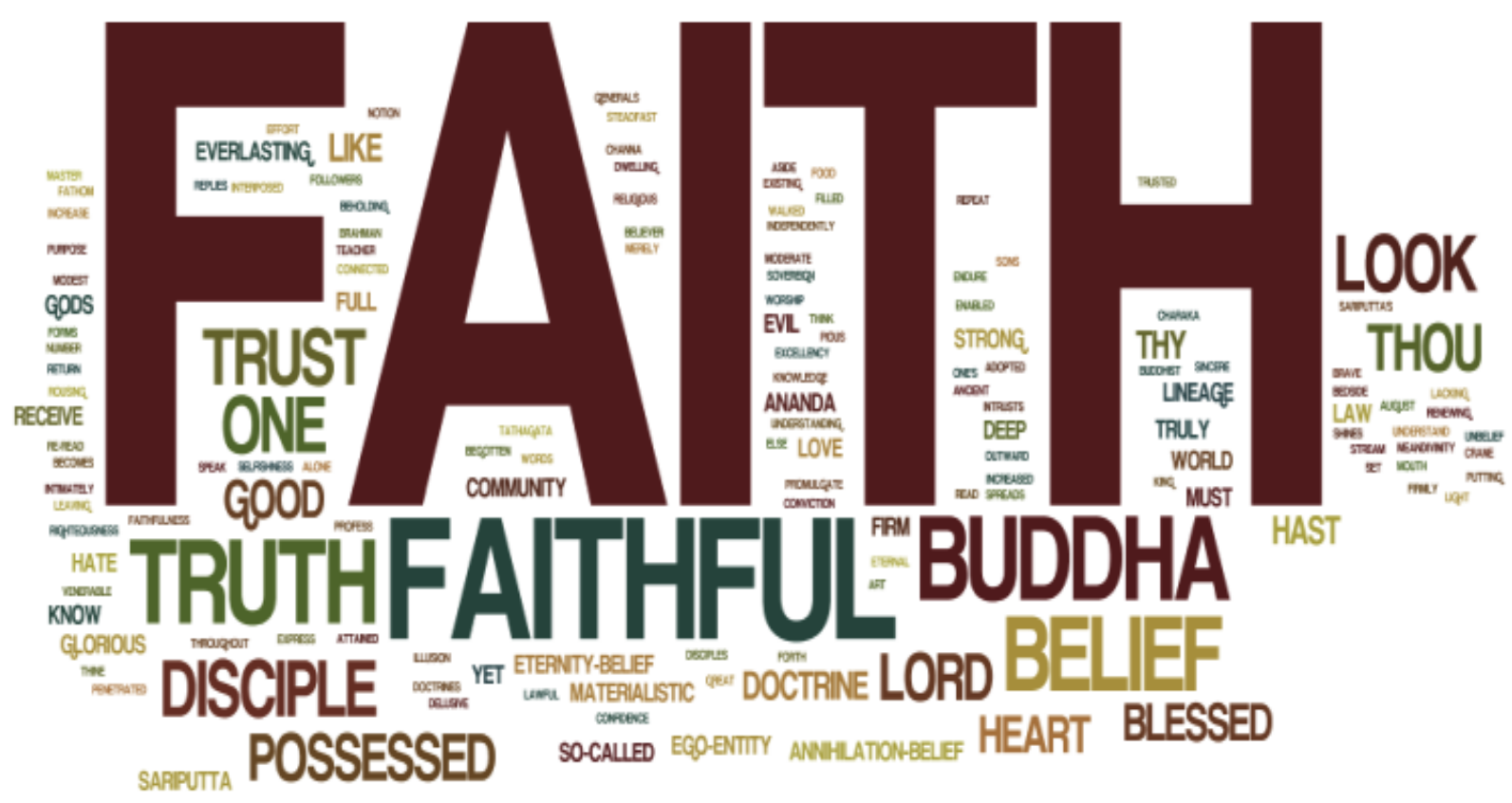

\section{Word Cloud for Hinduism}

The treatment of faith in the Hindu religion is much lighter than in other religions (Figure

4). The list of extracted concepts was short, despite the fact that there were many sacred texts from which to draw. The word cloud is interesting in that the majority of secondary references are not to substantive concepts related to faith. This suggests that the concept of faith in the Hindu religion is not as extensively developed or perhaps as core a tenet as in other religions. 
Figure 4.

Word Cloud for Faith in Hindu Religion
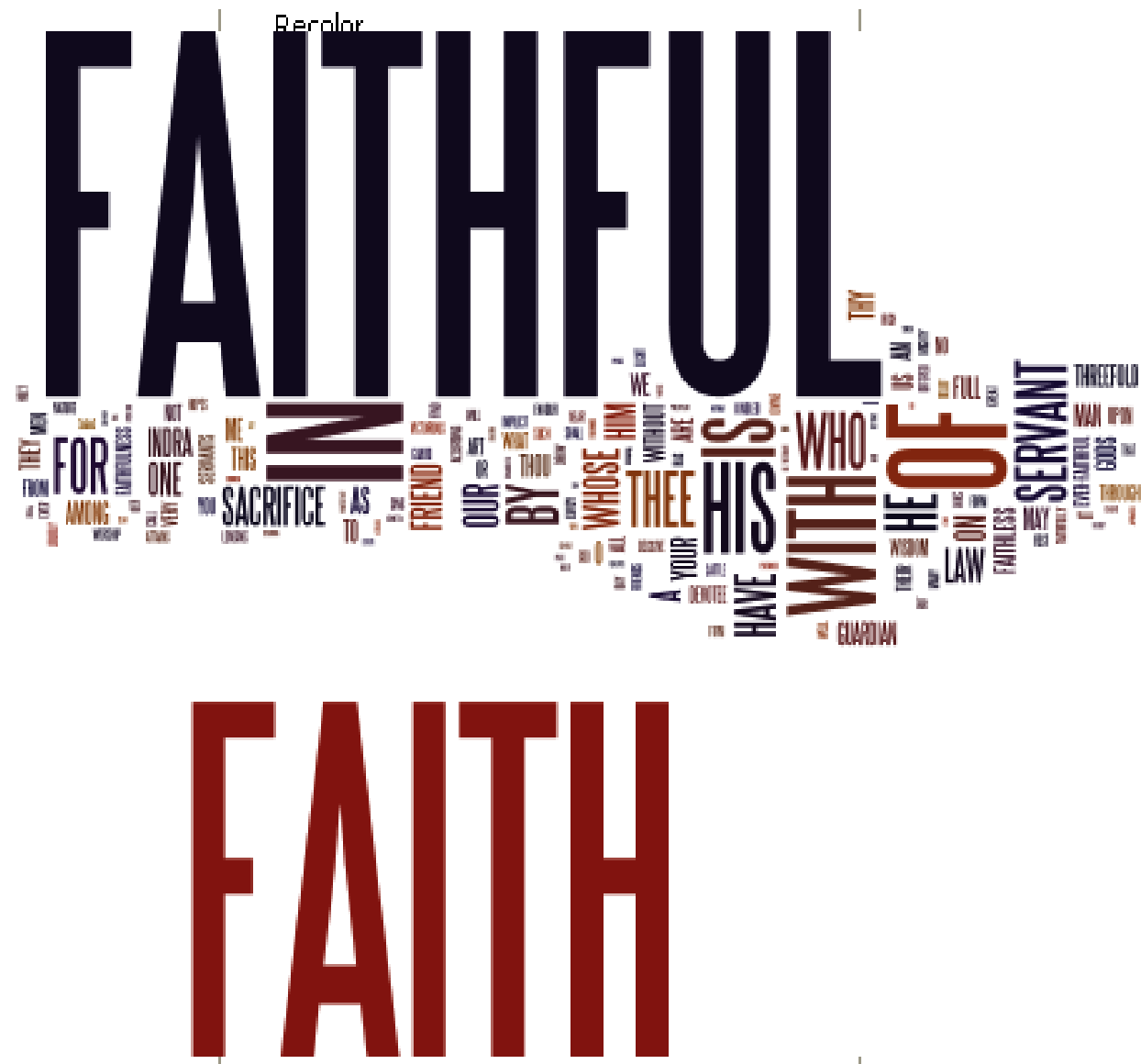

\section{Word Cloud for Islam}

Islam provided the second richest set of faith related concepts, second to the Christian religion. What is interesting about the word cloud for Islam is the heavy emphasis on the belief aspect of faith (Figure 5). Equivalent in intensity to belief is the pronoun, Who. This suggests that faith is a personal issue in Islam. While faith appears as a concept in the cloud, it is at a much lower level of intensity. Even more prominent than faithful are the concepts, Good and Do. The prominence of the concept - Who - suggests a personal and a behavioral aspect of faith. 
Figure 5.

Word Cloud for Faith in Islamic Religion

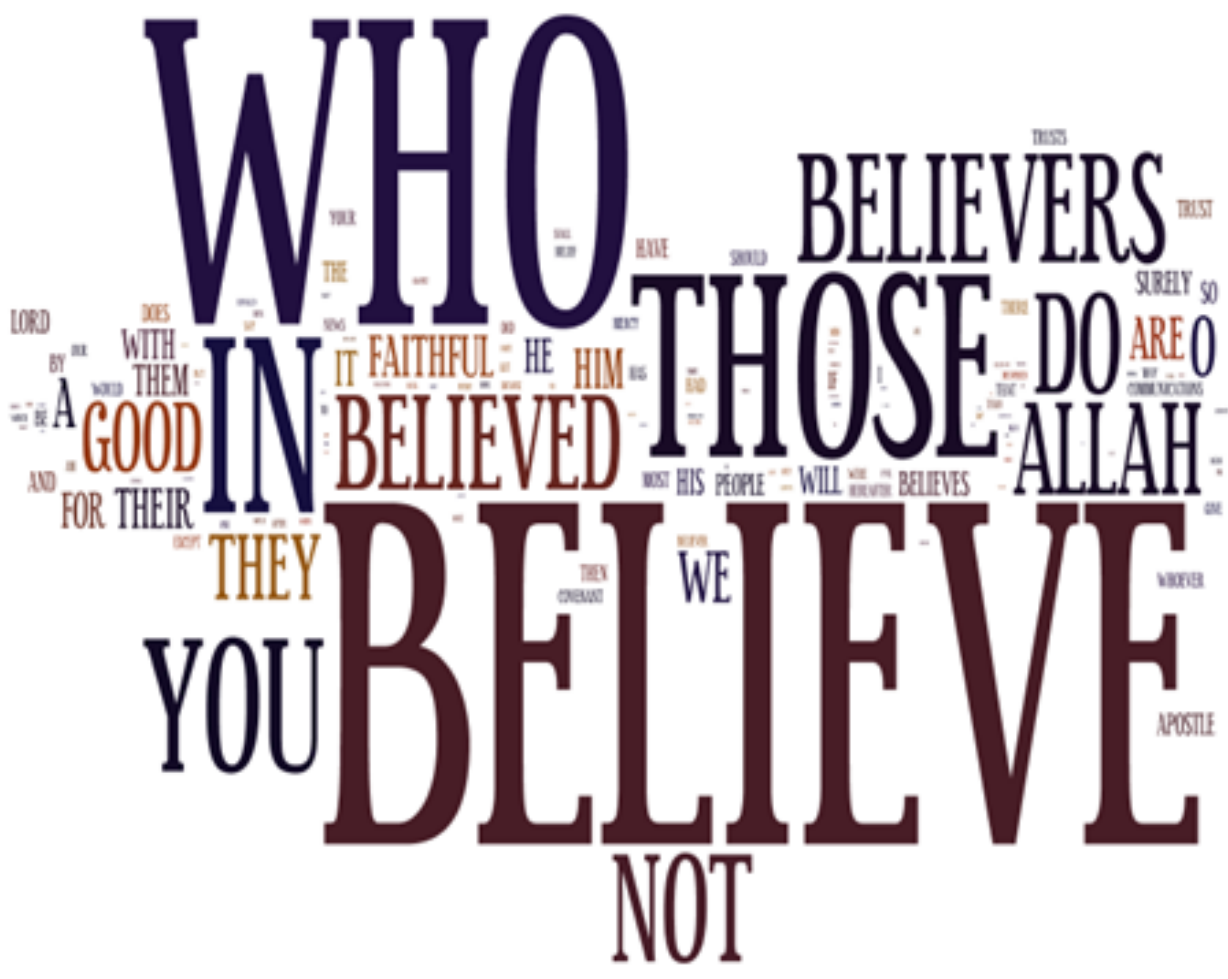

\section{Word Cloud for Jainism}

The word cloud for Jainism illustrates direct representation of faith concepts (Figure 6).

The concepts are sparse, though, in comparison to other religions such as Christianity and Islam. The secondary concepts for Jainism all pertain to individuals and behaviors. There are few if any other faith-related concepts visible in the word map. 
Figure 6.

Word Cloud for Faith in Islamic Religion

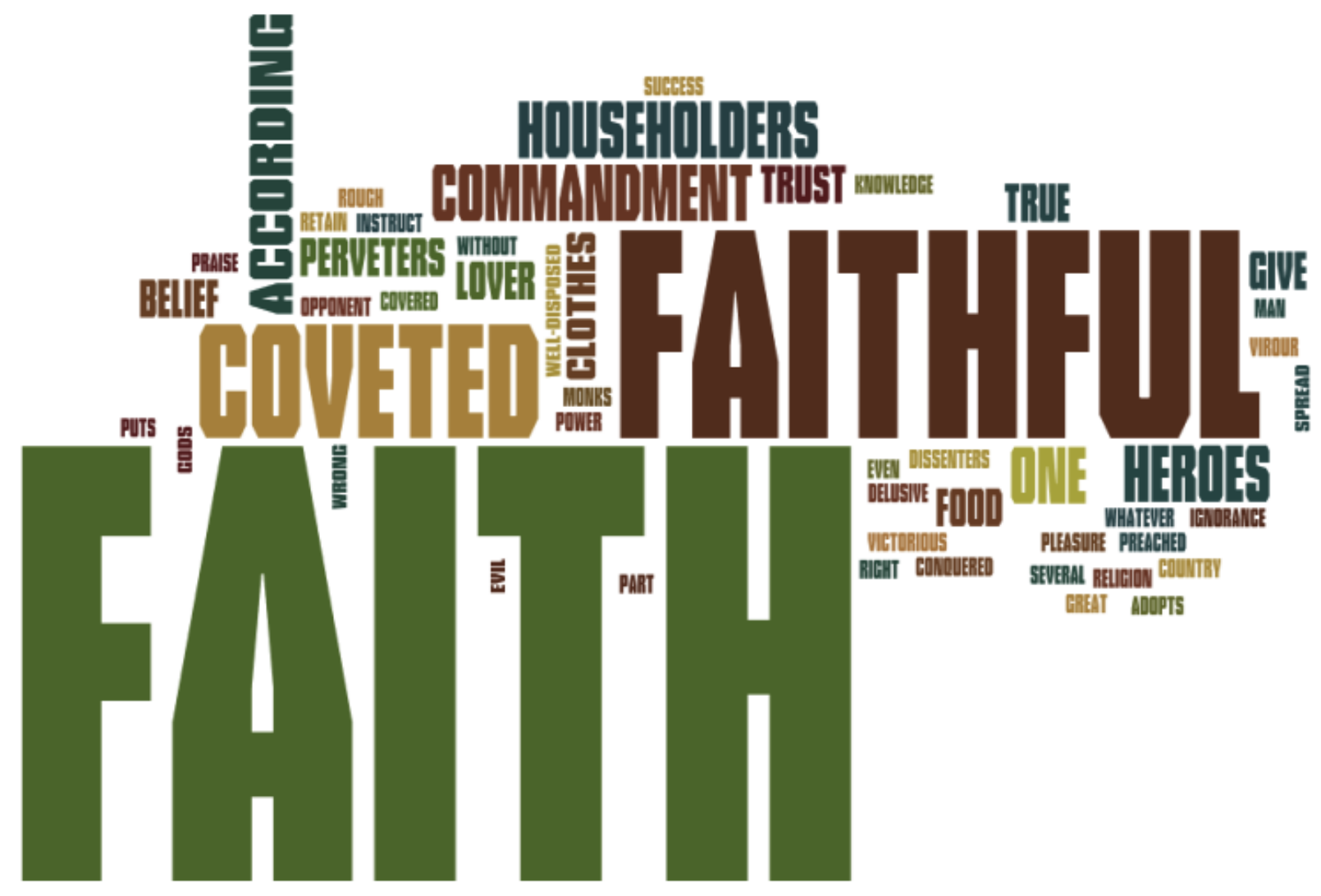

\section{Word Map for Taoism}

The word map for the Tao religion is sparse in comparison to other religions such as

Christianity and Islam (Figure 7). There are few secondary contexts supporting the references to faith in the sacred texts of Taoism. Trust is the only other faith-related concept that displays at a level of intensity in the word map. 
Figure 7.

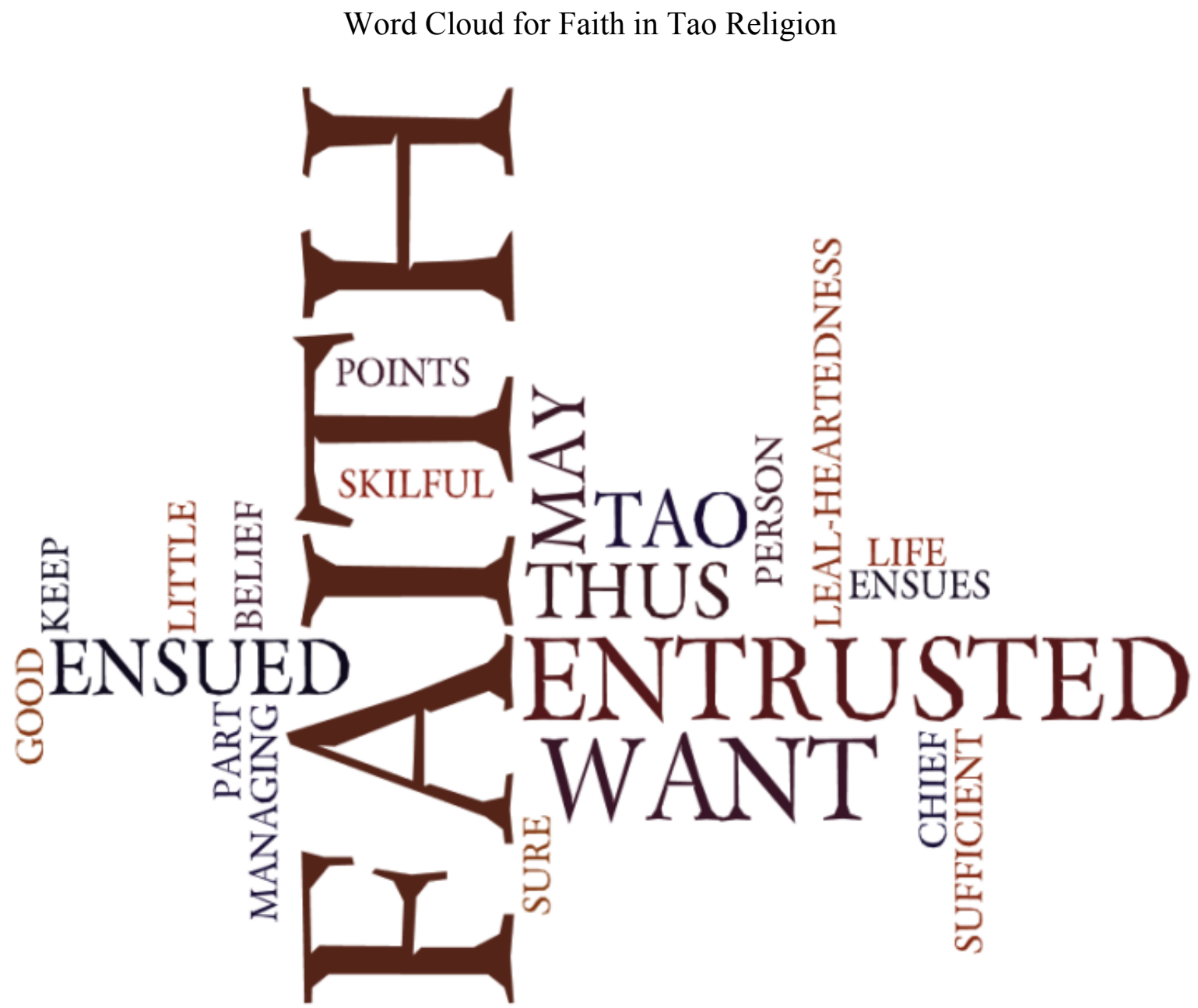

\section{Composite Word Map for Six Religions}

The composite word map for all six religions illustrates the strength of the two core concepts of faith - faith and belief - and all of their lexical variants (Figure 8). The word map shows the rich context that surrounds these core concepts when all religions are viewed together.

\section{Observation and Discussion of Research Results}

Our first research question asked whether it was possible to create a visual representation of faith drawing upon the use of key semantic concepts in the sacred texts of a religion. The research suggests that it is possible to create a visual representation of faith grounded in semantic 
concepts. What is not clear from the results is whether deriving the concepts from sacred texts alone is sufficient to describe different views of faith across religions.

Figure 8.

Composite Word Map for Six Religions

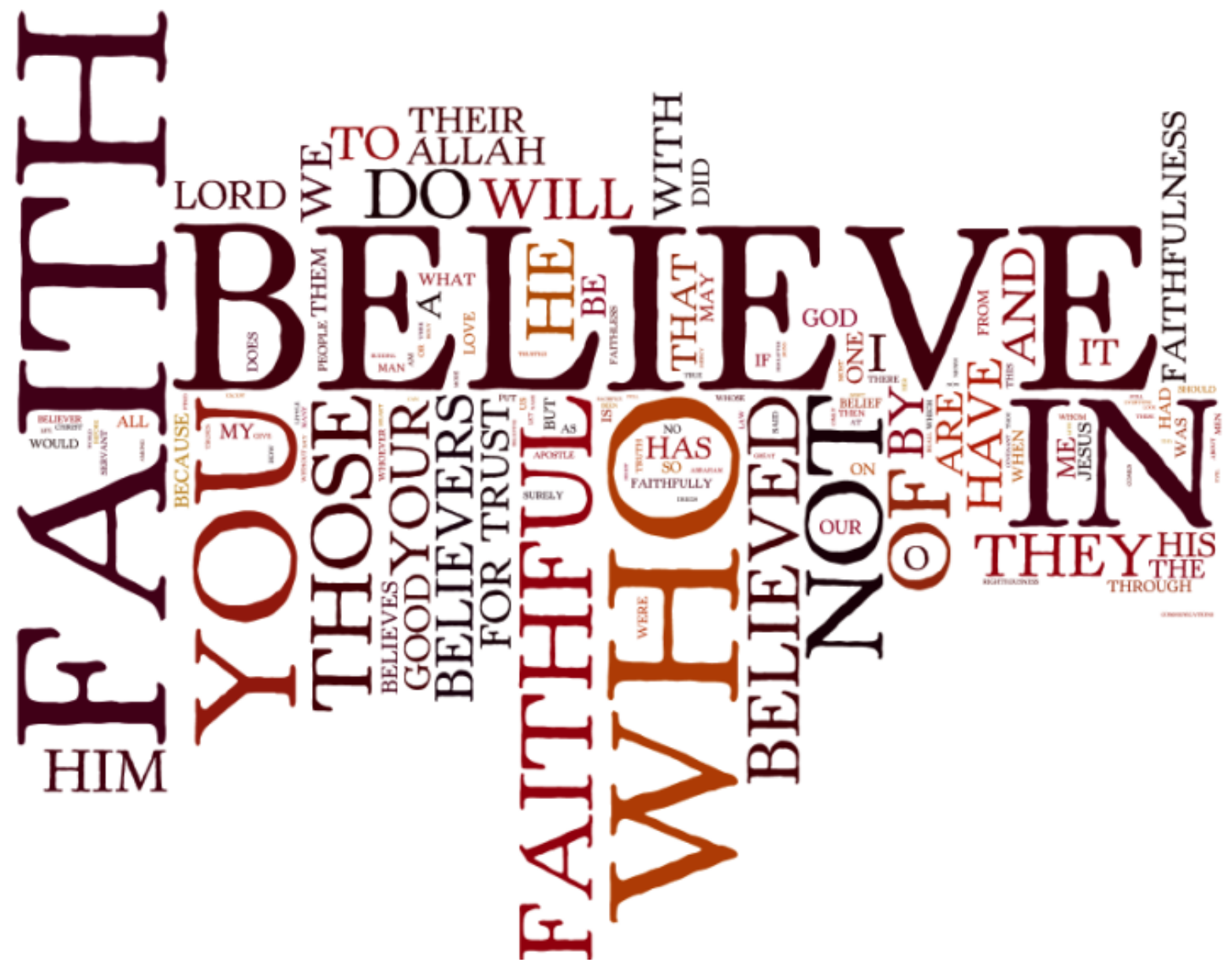

The second research question asked whether commonalities and variations in the concept of faith would be visible in the cloud representations. The research suggests that commonalities and variations are visible. Again, though, we do not know whether they are as robust as they might be. Extending the corpus beyond sacred texts to include other sources of religious information would provide a more rigorous test. 


\section{VISUAL EXPLORATION OF SEMANTIC MARKERS OF FAITH}

Our third research question asked whether the visual representation of faith was meaningful to members and non-members of the religious communities. The success or failure of this exploratory research will be judged by those who view and react to the word maps. Word maps based on sparse semantics may not be sufficient to support describe the context of faith in a particular religion. Reviews and responses also may suggest that a richer corpus is needed to ensure that the richness of the context reflects the richness of the religion.

The exploratory research illustrates the importance of a robust semantic definition and methodology for any visualization effort. Had the research been grounded in a simple representation of faith and its lexical variants, the differences across religions would not have been as obvious. The exploratory research also illustrates the importance of selecting the corpus for analysis. The current work includes only sacred texts for concept extraction and categorization. Had we extended the corpus to include other sources of religious information for each of the religions, the maps may have demonstrated richer semantic contexts and meaning. 
VISUAL EXPLORATION OF SEMANTIC MARKERS OF FAITH

\section{References}

Arnold, E. (1993). Bhagavad-Gita. Dover Publications, New York.

Ashton, W. G., translator (1896). The Nihongi. http://www.sacred-texts.com/shi/ (Accessed online April 30, 2012)

As-Sibaa'ie, M. (2004). Civilization of Faith. A Journey through Islamic History. International Islamic Publishing House, Riyadh, Saudi Arabia.

Jacobi, H., translator. Akaranga Sutra.

http://www.hinduwebsite.com/sacredscripts/jainscripts/akaranga.asp (Accessed online on April 30, 2012)

Jacobi, H., translator. Holy Kalpa Sutra. http://www.sacred-texts.com/jai/kalpa.htm (Accessed online on April 30, 2012)

King, W. L. (1964). In the hope of Nibbanna: an Essay on Theravada Buddhist Ethics. Open Court Publishing,

Legge, J. (1893). The Confucian Cannon in Chinese and English. http://www.sacredtexts.com/cfu/cfu.htm (Accessed online on April 30, 2012).

Legge, J. The Five Classics. http://www.sacred-texts.com/cfu/index.htm\#fivecla (Accessed online on April 30, 2012.

Legge, J. (1895) The Sacred Books of China. http://www.sacredtexts.com/cfu/index.htm\#sbechinaBhagavad-gita (Accessed online on April 30, 2012)

Legge, J. translator (1891) Tao Te Ching. http://www.sacred-texts.com/tao/taote.htm (Accessed online on April 30, 2012)

Legge, J. translator (1891). The Texts of Taoism. Part I. http://www.sacredtexts.com/tao/sbe39/index.htm (Accessed online on April 30, 2012). 


\section{VISUAL EXPLORATION OF SEMANTIC MARKERS OF FAITH}

Legge, J. translator (1891). The Texts of Taoism. Part II. http://www.sacredtexts.com/tao/sbe40/index.htm (Accessed online on April 30, 2012)

Mawdudi, S. A. A. (1988). Towards Understanding Islam. Islamic Teaching Center. Lahore, India.

Shakir, M.H. (1983). The Koran. Tahrike Tarsile Qur'an Publisher, Inc. http:/quod.lib.umich.edu/k/koran/ (Accessed online April 30, 2012).

Strong, J. (2010). The New Strong's Expanded Exhaustive Concordance Of The Bible. Red Letter Edition. Thomas Nelson Publishers, Nashville TN.

The Vedas http://www.hinduwebsite.com/vedicsection/vedaindex.asp (Accessed online on April 31, 2012)

Tsering, G. T. (2005). The Four Noble Truths: The Foundation of Buddhist Thought, Volume 1. Wisdom Publications, 2005.

Von Denffer, A. (1988) A Day with the Prophet. The Islamic Foundation. Leicester, U. K.

Zaehner, R. C. (1969) Hinduism. Oxford University Press, London. 
VISUAL EXPLORATION OF SEMANTIC MARKERS OF FAITH

\section{Biographical Sketch}

Denise Bedford is currently the Goodyear Professor of Knowledge Management at the College of Communication and Information, Kent State University. She teaches courses in knowledge management, communities of practice, economics of information, semantic analysis, enterprise architecture, business intelligence, organizational network analysis, and information environments. Her educational background includes a B.A. in History, in Russian Language/Literature, and in German Language/Literature from the University of Michigan; an M.A.in Russian History also from University of Michigan; an M.S. in Librarianship from Western Michigan University, and a Ph.D. in Information Science from University of California, Berkeley. 